\title{
TECNOLOGIA EM TEMPOS DE PANDEMIA: A EDUCAÇÃO A DISTÂNCIA ENQUANTO PANACEIA TECNOLÓGICA NA EDUCAÇÃO BÁSICA
}

\author{
Vitor Malaggi ${ }^{1}$
}

\begin{abstract}
Resumo: O presente ensaio tem por objetivo discutir a adoção da Educação a Distância (EaD) na Educação Básica, efetivada por diferentes redes de ensino no Brasil em tempos de pandemia causada pela COVID-19. Especificamente, intenciona problematizar em que medida tal contexto sociotécnico e educativo constitui um rebaixamento da formação humana integral enquanto projeto político-pedagógico, bem como da própria $\mathrm{EaD}$ enquanto modalidade educativa, a um conjunto de relações instrumentais tecnologicamente mediatizadas. Para tanto, serão efetivadas análises em torno dos conceitos de técnica, tecnologia, neutralidade da tecnologia e racionalidade tecnológica, tal como propostos no pensamento filosófico de Herbert Marcuse - autor ligado a Teoria Crítica da Sociedade. Tendo por base estes conceitos e demais discussões do campo pedagógico, será analisado o caso de adoção da EaD e seus suportes tecnológicos na Educação Básica pela Rede Pública de Ensino do Estado de São Paulo, na condição de estratégia para a reposição de aulas regulares presenciais no contexto pandêmico.
\end{abstract}

Palavras-chave: Educação a Distância. Educação Básica. Racionalidade tecnológica. Teoria Crítica. Herbert Marcuse.

\section{TECHNOLOGY IN TIMES OF PANDEMIC: DISTANCE EDUCATION AS A TECHNOLOGICAL PANACEA IN BASIC EDUCATION}

\begin{abstract}
This essay aims to discuss the adoption of Distance Education (EAD) in Basic Education, effectuated by different education networks in Brazil in times of pandemic caused by COVID-19. Specifically, it intends to problematize the extent to which this socio-technical and educational context constitutes a downgrade of integral human formation as a politicalpedagogical project, as well as of DE itself as an educational modality, to a set of technologically mediated instrumental relations. For this purpose, analyzes will be performed around the concepts of technique, technology, technology neutrality and technological rationality, as proposed in the philosophical thought of Herbert Marcuse - author linked to the Critical Theory of Society. Based on these concepts and other discussions in the pedagogical field, the case of adoption of distance education and its technological supports in Basic Education by São Paulo State's Public Education Network will be analyzed, as a strategy for replacing regular face-to-face classes in the pandemic context.
\end{abstract}

Keywords: Distance Education. Basic Education. Technological rationality. Critical Theory. Herbert Marcuse

\footnotetext{
${ }^{1}$ Mestre em Educação (UPF). Professor Efetivo na Universidade do Estado de Santa Catarina (UDESC). Endereço postal: Servidão Salvatina Feliciana dos Santos, 155. Itacorubi. Cep: 88034-600. Florianópolis/SC. E-mail: vitor.malaggi@udesc.br.
} 


\section{Para iniciar o diálogo...}

Na mitologia grega, Panaceia era a deusa da cura. Seu nome deriva dos termos gregos pan (todo) e akos (remédio), em alusão ao fato de que Panaceia era capaz de curar todas as enfermidades que assolam o humano. É neste sentido que, na linguagem popular, o termo "panaceia" passa a ser utilizado com o significado de "remédio para todos os males". Ou, em sentido figurado, "o que se emprega para remediar dificuldades". Nos parece ser esta metáfora mitológica adequada para pensar o status que a tecnologia alcançou na sociedade capitalista hodierna, racionalizada desde suas entranhas a partir do atravessamento totalitário de valores como "eficácia", "eficiência" e "padronização" enquanto ideias-forças de organização, pensamento e comportamento do/no tecido sócio-histórico. A tecnologia tornou-se uma panaceia: no jogo entre "fins e meios" que abrangem e delimitam os problemas sociais em suas possibilidades históricas, não se discutem mais os fins (os "porquês"), somente os meios (o "como"). E os meios, como bem destaca Marcuse, são técnicos; a racionalidade que Ihe dá sentido, ao abordar o real "[...] como instrumentalidade que se presta a todo propósito e finalidade [...]", é tecnologia: tecno + logos. (MARCUSE, 2015, p. 162).

Portanto, configura-se aqui uma abordagem tecnológica da realidade, que resultará otimizada em suas possibilidades tanto mais recursos técnicos compreendidos como "panaceia" - forem agenciados como fonte de resolução de todo e qualquer problema humano. Inclusive - e por que não, diriam alguns... - problemas de ordem educacional. É justamente uma perspectiva histórica acerca da realidade humana que, neste contexto, sofre seu maior revés. No fetichismo do qual tais técnicas emergem como seres dotados de poderes universais e caráter autônomo, a história passa de criação consciente de homens e mulheres face aos desafios da existência a uma espécie de autopropulsão amorfa, guiada a partir de poderes pouco compreendidos pelos sujeitos no seio das relações sociais que os constituem. Destes poderes autônomos, talvez a tecnologia constitui nas sociedades hodiernas como aquele que sintetiza formas objetivas e subjetivas da mais racionalizada submissão dos seres humanos a suas próprias criações, confiando nelas um caráter messiânico ou, justamente, de panaceia tecnológica. 
Em sentido análogo, não constitui fato recentíssimo no debate educacional tomando-se aqui o século XX como recorte temporal -, o surgimento de propostas sobre o ensinar-aprender que enxergavam na realização tecnológica do pedagógico uma nova versão da panaceia anteriormente identificada, agora em sua especificidade de "panaceia tecno-educacional". De pedagogias "centradas na criança", em que materiais instrucionais desautorizavam a intervenção pedagógica do adulto como elemento relevante dos processos de ensinar-e-aprender; perpassando pela noção pedagógica de que os processos educativos devem ter como objetivo formativo nuclear o "aprender a aprender", sendo sua forma de realização par excellence a apropriação do método científico tal como sistematizado na ciência (da natureza) moderna; à inserção de "máquinas de ensinar" que automatizavam a intervenção do(a) educador(a), otimizando-a e tornando-a personalizada e eficiente - tal ideário tecnológico vai sendo gestado no âmbito pedagógico do século $X X$ como solução que emerge de diferentes concepções acerca dos problemas da formação humana. Tão díspares, mas, no sentido aqui problematizado, tão próximas entre si como no escolanovismo e na compreensão behaviorista da aprendizagem humana.

No contexto sociotécnico de um século XXI ainda em seu limiar, contudo, tornase possível afirmar que tal ideário tecno-educacional (re)configura-se em termos cada vez mais totalitários. O universo do discurso educacional hegemônico remete-se a este ideário de forma incessante e nitidamente hipnótica - "inovação" é sua palavra de ordem; "tecnologia" (ou "tecnológica"), é sua predicação possível e necessária. No âmago pedagógico do qual derivam tais palavras de ordem, reside invariavelmente um pensar e comportar-se acerca do educacional que repete a racionalidade anteriormente identificada, centrada sempre nos "meios", nunca na problematização dos "fins". A esta racionalidade tecno-educacional, questionamentos como os de Paulo Freire - realizado no "longínquo" ano de 1984 acerca da Informática na Educação -, Ihes parece totalmente sem sentido, improdutivos e ineficientes: "Para mim, a questão que se coloca é: a serviço de quem as máquinas e a tecnologia avançada estão?" (FREIRE, 1984, p. 1).

Obviamente, não estamos aqui defendendo um anacronismo tecnófobo a priori, que descarta possibilidades pedagógicas em torno dos artefatos técnicos, sem ao 
menos questionar-lhes como um dos possíveis elementos constituintes de processos educativos que mirem a formação integral do ser humano como objetivo estratégico. Trata-se, pois, de a reflexão crítica intencionar um adentramento profundo das camadas constitutivas de uma racionalidade que provê sentido ao técnico, enquanto lógica constituinte. Uma racionalidade tecno-educacional que, em nome da abordagem instrumental dos problemas da formação humana, naturaliza as tecnologias-em-si como panaceias capazes de resolver de forma igualmente instrumental tais problemas identificados. A racionalidade tecno-educacional constituise, então, como ideologia pedagógica.

Como forma de tecer algumas análises acerca do objeto acima identificado, entendemos ser necessário partir de uma realidade educativa concreta em que tal fenômeno se constitui. Assim, o objetivo deste ensaio será o de discutir em que medida a adoção da Educação a Distância $(\mathrm{EaD})$ na Educação Básica, efetivada por diferentes redes de ensino no Brasil em tempos de pandemia causada pela COVID19 , constitui um rebaixamento da formação humana integral enquanto projeto políticopedagógico, bem como da própria $\mathrm{EaD}$ enquanto modalidade educativa, a um conjunto de relações instrumentais tecnologicamente mediatizadas. Para tanto, o presente ensaio resultará dividido em 3 momentos: inicialmente, em torno da análise dos conceitos de técnica, tecnologia, neutralidade da tecnologia e racionalidade tecnológica, tal como propostos no pensamento filosófico de Herbert Marcuse.

Tendo por base estes conceitos e demais discussões do campo pedagógico, serão apresentados e analisados alguns aspectos de um caso específico de adoção da EaD e seus suportes tecnológicos na Educação Básica, pela Rede Pública do Estado de São Paulo, na condição de estratégia para a reposição de aulas regulares presenciais no contexto pandêmico. Em conclusão, discutiremos acerca do papel da Educação e, também, da luta pela sua valorização e de seus profissionais em um contexto social atípico causado pela pandemia. Contexto que nos coloca opções sobre o que desejamos para a sociedade brasileira e, em última instância, para o futuro da humanidade.

\section{Tecnologia e técnica: análises conceituais a partir de Herbert Marcuse}


Para a análise dos conceitos de técnica, tecnologia, neutralidade da tecnologia e racionalidade tecnológica em Herbert Marcuse, autor vinculado a Teoria Crítica da Sociedade, partiremos de suas considerações no texto Algumas implicações sociais da tecnologia moderna, escrito em 1941. Apesar do hiato temporal desde sua escrita, cremos que as reflexões desveladas por Marcuse configuram-se ainda de extrema relevância para a análise do fenômeno tecnológico na sociedade hodierna.

Neste ensaio, a posição do autor é clara: não interpreta o fenômeno tecnológico no vácuo, mas o encara como processo social desde sua gênese. Isto quer dizer, dentre outras coisas, que são os homens e mulheres em dadas condições históricas e a partir de suas necessidades de (re)produção da existência consequentemente, da própria sociedade que criam por meio destas relações -, que compõem o fenômeno tecnológico ao dar-Ihe um sentido intencional dentro e a partir do tecido social. É com base em tal assunção que a distinção entre técnica e tecnologia desenhada pelo autor ganhará em profundidade reflexivo-crítica. A técnica, enquanto conjunto de procedimentos organizados e/ou artefato que objetiva em si modos de proceder e atuar sobre a realidade (natural e sócio-histórica), não passa de uma dimensão do fenômeno tecnológico, importante obviamente, mas não totalizadora do que significam tais artefatos quando "ganham vida" no âmbito das relações sociais.

Logo, "tecnologia" em Marcuse configura um conceito que exprime a concretude social enquanto totalidade de maior grau de abrangência, ao constituir-se como "modo de produção" das relações sociais. Para a constituição de tal "modo de produção" do social, diversos artefatos técnicos podem ser agenciados na condição de parcialidades. Parcialidades com intencionalidade tecnológica que as constituem desde seu interior - e isto quer dizer, desde sua gênese social -, ao serem direcionadas por este ou aquele grupo de seres humanos, que lançam mão de certos artefatos técnicos a partir de objetivos definidos e por tais grupos levados a cabo tecnologicamente. A condução tecnológica da realidade social, por sua vez, dialeticamente incide sobre a totalidade dos sujeitos nela presente e, logo, vai igualmente configurando formas técnicas de pensar e se comportar frente aos 
Criar Educação, Criciúma, v. 9, oㅡ, Edição Especial 2020.- PPGE - UNESC - ISSN 2317-2452

problemas que deste contexto emergem. É neste sentido que o autor refere-se a tecnologia tanto como a "[...] totalidade dos instrumentos, dispositivos e invenções que caracterizam a era da máquina", quanto a "[...] uma forma de organizar e perpetuar (ou modificar) as relações sociais, uma manifestação do pensamento e dos padrões de comportamento dominantes, um instrumento de controle e dominação." (MARCUSE, 1999, p. 73).

Com base nesta distinção, podemos afirmar com Marcuse a impossibilidade da neutralidade da tecnologia, posto que a sua forma de existência é eminentemente social; logo, voltada para finalidades especificamente definidas pelos seres humanos em um dado contexto histórico. Importante perceber criticamente, portanto, que Marcuse ao afirmar "A técnica por si só pode promover tanto o autoritarismo quanto a liberdade, tanto a escassez quanto a abundância, tanto o aumento quanto a abolição do trabalho árduo" (MARCUSE, 1999, p. 74), não resvala em uma aporia argumentativa que militaria contra o princípio da não neutralidade da tecnologia. Isto porque não existe técnica no vácuo, mas somente enquanto fenômeno historicamente situado e datado. O que significa dizer, em outras palavras, que toda técnica somente ganha sua "razão de ser" quando criada e direcionada para determinadas formas de sua utilização na constituição da realidade, enquanto "modo de produção", pelos grupos sociais que a ela conferem intencionalidade tecnológica. A questão que podemos aventar, na análise do fenômeno tecnológico (também em nosso contexto social contemporâneo), é de quem lança mão de um dado conjunto de técnicas e para alcançar quais objetivos sociais (finalidades tecnológicas).

É importante sublinhar a luz que Marcuse lança para pensar a não neutralidade da tecnologia, ao afirmar que são os "[...] grupos sociais que direcionam sua aplicação e utilização." (MARCUSE, 1999, p. 73). E, ao passo em que cada vez mais a tecnologia se firma como fator axial do modo de produção e reprodução das sociedades, quanto mais adentra ao tecido social a partir da visão de certos grupos que acabam por direcionar-Ihe a forma de "ser e existir" nas relações sociais, tão mais enigmático o fenômeno tecnológico acaba por se tornar aos sujeitos que dele participam de forma apenas periférica. Quer dizer, como consumidores ou apêndices das características que os artefatos técnicos imprimem na sua condução social, a 
partir de demandas que Ihes são estranhas. Temos aqui um potencial imenso de alienação - estranhamento dos sujeitos frente ao fenômeno tecnológico que, conforme denunciou Marcuse (1999, p.73), acabam por moldar formas de "[...] manifestação do pensamento e [...] padrões de comportamento dominantes."

A técnica torna-se reificada, ou seja, é desnudada de seus aspectos sóciohistóricos e aparece aos sujeitos somente em sua dimensão instrumental - enquanto "puro" meio ou forma de agir sobre a realidade. Uma realidade social que também será compreendida por tal racionalidade como um sistema instrumental hipotético, passível de ser tecnicamente calculado, manipulado e organizado. (MARCUSE, 2015, p. 160). Novamente, a questão possível a partir de Marcuse residiria em torno da relação tecnológica dos meios com suas finalidades. Talvez um dos fenômenos mais evidentes da alienação que os seres humanos contraem, frente às criações técnicas na sociedade contemporânea, seja justamente o maravilhamento com que as encaram (ou são levados a encarar...). Tal maravilhamento surge desta dissociação entre técnica e tecnologia na consciência e na prática social dos sujeitos, da incompreensão gerada pela naturalização do fenômeno tecnológico na sociedade. Como bem destaca Vieira Pinto (2005, p. 35),

O homem maravilha-se diante do que é produto seu porque, em virtude do distanciamento do mundo, causado pela perda habitual da prática de transformação material da realidade, e da impossibilidade de usar os resultados do trabalho executado, perdeu a noção de ser autor de suas obras, as quais por isso lhe parecem estranhas.

Logo, a tecnologia aparece como um ente a-histórico - portanto, naturalizado, ou até mesmo como elemento exteriormente inserido na História (História com $\mathrm{H}$ maiúsculo, vide as noções de progresso atrelada às tecnologias, reproduzidas no discurso de senso comum). Resulta, deste contexto, possibilidades de compreensão limitadas (e ideologicamente direcionadas) do fenômeno tecnológico. Se aos sujeitos pode Ihes parecer evidente, em um primeiro momento, que a tecnologia possui relação com diversos campos da produção da existência humana - basta observar o adentramento cada vez mais agudo dos artefatos digitais nos diversos ramos de sua atuação -, tal assunção não é tão óbvia quando problematizamos como e porque a 
tecnologia ajuda a "[...] perpetuar (ou modificar) as relações sociais." (MARCUSE, 1999, p. 73).

$\mathrm{Na}$ verdade, ao se ter uma relação com as tecnologias somente em viés alienado/reificado, enquanto um "objeto quase-mágico" que possibilita realizar ações padronizadas as quais, muitas vezes, pouco compreendemos em seu(s) "porquê(s)" no seio das relações sociais - tão somente nos contenta o seu aspecto operacionalfuncional -, a questão do "perpetuar X modificar" sequer faz-se um percebido destacado na consciência dos sujeitos. As noções de que a tecnologia pode ser equiparada a "modernização", "progresso" ou "inovação" são, pois, justamente o epifenômeno ideológico desta relação acrítica dos sujeitos com o fenômeno tecnológico, em nível de consciência ingênua (isto é, aquela que não consegue de forma crítica captar as relações conflituosas entre a totalidade do fenômeno socialtecnológico e a utilização massiva de artefatos técnicos como parcialidade deste). Desde que funcional e operacional, a "razão de ser" do artefato técnico encerrado em si mesmo se torna verdade autovalidante - quem poderia, afinal, questionar suas diversas "benesses" sem temer ser considerado um "atrasado" ou "anacrônico"?

É por isso que Marcuse aponta, como dimensão do fenômeno tecnológico nas sociedades industriais avançadas (MARCUSE, 2015), a sua constituição enquanto racionalidade que se entranha nos recantos mais íntimos da subjetividade dos sujeitos. Homens e mulheres passam a organizar tecnicamente sua relação com o mundo e os outros, a partir de formas de pensar e comportar-se padronizadas e afeitas a racionalidade dominante. Resulta evidente para Marcuse, pois, que a tecnologia enquanto modo de produção da existência possui grande probabilidade de ser utilizada como "[...] um instrumento de controle e dominação". Contudo, nos parece igualmente relevante apontar aquilo que Marcuse, de certa forma, "esconde" dentro de parênteses - "ou modificar". (MARCUSE, 1999, p. 73). Ou seja, a dualidade que o autor parece apontar no fenômeno tecnológico que, não sendo a-histórico e, portanto, produção humana em aberta possibilidade de (re)apropriação concreta para finalidades diversas, poderia ser agenciado para a práxis de transformação emancipatória das relações sociais. 
Mesmo assim, não podemos encarar que a palavra "modificação", em si e necessariamente, traga algum conteúdo politicamente orientado para a superação das formas de opressão também pela apropriação crítica da tecnologia nas sociedades contemporâneas. De fato, a sociedade capitalista é aquela que, ao longo da história, mais se reestruturou (modificou a si mesma) justamente pelo papel que as tecnologias tiveram na composição deste modo de produção. Marx (2013, p. 427) nos lembra do poder que as relações capitalistas de produção possuem na superação de suas crises, justamente pela revolução constante que infligem ao desenvolvimento das forças produtivas - sendo as tecnologias um dos seus componentes fundamentais na indústria moderna, fator sine qua non de sua própria manutenção. A necessidade estrutural de "modificar para permanecer" das relações sociais capitalistas é fecunda para a abertura de novos mercados, novas tendências ou "propostas inovadoras" que intencionam espraiar-se de forma totalitária ao todo social, como necessidade superimposta. Para Marcuse (1999), formas de se levar a racionalidade (tecnológica) do sistema para cada recanto da existência social.

Mudar para permanecer, portanto, nos leva a uma possibilidade inclusive de dialetizar a mudança ressaltada por Marcuse (1999), o que reconduz, pois, ao debate da não neutralidade da técnica, tendo em vista que não existe objeto técnico fora das relações sociais. Logo, o objeto técnico ganha sua razão de ser justamente por estar inserido na totalidade maior do fenômeno tecnológico, que desnuda a noção de que cada criação dos seres humanos é historicamente situada e condicionada pelas formas como homens e mulheres, organizando a sua existência, lançam mão destes objetos para dar conta do "desafio de viver". Percebe-se no pensamento de Marcuse, enfim, que sua preocupação no campo de investigação da relação sociedade tecnologia não recai somente numa noção estreita de "modo de produção", atrelada a infraestrutura econômica que, sendo fundamental, não justifica-se em sua existência aos indivíduos se estes não a aceitarem ou nele crerem. Isto é, se a forma como a sociedade é racional e tecnologicamente organizada não lhes é inculcada enquanto "positividade", advinda dos motivos socialmente expressos pelos grupos dominantes do porquê de os artefatos técnicos serem ocupados desta ou daquela forma, para esta ou aquela finalidade social. 
Para dar conta desta inculcação, constrói-se uma nova forma histórica de se relacionar com o fenômeno tecnológico e com a realidade a partir dele, que Marcuse (2015) denominou de "racionalidade tecnológica". Para Marcuse, trata-se da forma padronizada e operacional de "atuar na" e "pensar a" realidade, que incorporada na subjetividade dos sujeitos reduz a capacidade reflexivo-crítica de "negação" do pensamento humano. Ou seja, sua capacidade de transcender os fatos dados, de situá-los em um contexto mais amplo e histórico - logo, de realizar-se enquanto movimento reflexivo de "totalidade" e "crítica". É, pois, a racionalidade ligada aos ditames pragmáticos de valores como "otimização", "evolução", "eficácia", "progresso", "modernização", "inovação" e "eficiência", todos eles ideologicamente percebidos como "fatores positivos em si", desnudados dos interesses políticoeconômicos que os guiam em sua aplicação na realidade social (MARCUSE, 2015).

Neste mundo tecnificado, "[...] a 'pura instrumentalidade' e 'eficácia' de organizar meios e fins dentro de um universo pré-estabelecido [isto é, de fins que foram superimpostos aos sujeitos] é o 'princípio comum de pensamento e ação'." (KELLNER, 2015, p. 20). Logo, a racionalidade tecnológica é, ao mesmo tempo, causa e efeito do contexto social em que a neutralidade da tecnologia elevou-se a condição ideológica, enquanto discurso que visa obliterar a capacidade dos sujeitos em enxergar o fenômeno tecnológico em suas formas concretas de socialmente se manifestar. Marcuse sintetiza na ideologia das sociedades industriais avançadas como a "[...] racionalidade técnico-científica e a manipulação fundiram-se em novas formas de controle social." (MARCUSE, 2015, p. 155). Ou seja, a racionalidade tecnológica é, ao mesmo tempo, um fato objetivo e subjetivo, sendo que a mediação destes planos na relação entre consciência e realidade de dominação ocorre no campo da ideologia, enquanto condição sine qua non de reprodução objetiva do social pela via de sua reprodução subjetiva como "falsa consciência".

Pela via desta racionalidade, o fenômeno tecnológico tende a se tornar totalitário, pois ao determinar de antemão o "o quê", o "quando" e o "como" socialmente positivado, molda cada sujeito em suas necessidades e aspirações como reflexo desta sociedade, ente passivo e reprimido na/da "engrenagem social". 


\section{Educação a Distância na Educação Básica: o caso da Rede Estadual de Ensino do Estado de São Paulo}

A adoção da Educação a Distância (EaD), ou de uma certa compreensão do que seja EaD (atualmente transmutada em "Ensino Remoto"), enquanto remédio para a "cura" da impossibilidade de realização dos processos formativos presenciais na Educação Básica, ganha relevo atualmente como panaceia tecno-educacional em tempos de pandemia. Especificamente, o caso a ser aqui abordado é o da Rede Pública de Ensino do Estado de São Paulo, pela profundidade com que a "solução tecnológica" vem sendo utilizada tendo em vista a reposição de aulas regulares presenciais. Contudo, cremos que uma pesquisa mais detida por outras "soluções tecnológicas" adotadas em redes de ensino no Brasil apontarão cenário semelhante, reservadas as possíveis especificidades de cada contexto.

Frente ao contexto pandêmico, o site da Secretaria de Educação do Estado de São Paulo reporta notícia veiculada em 22 de abril, com a seguinte manchete: "Educadores já podem se replanejar para a volta às aulas no dia 27 ". Anteriormente, o Governo de SP havia antecipado as férias e recesso escolar de 150 mil professores da rede estadual, com início a partir de 23 de março - portanto, exato 1 mês antes da publicação da notícia informando sobre a volta às aulas. Nesta, lê-se:

Com o objetivo de preparar a equipe escolar para o retorno às aulas dos 3,5 milhões de alunos na próxima segunda-feira (27), os professores e gestores das escolas estaduais participam de hoje a sexta-feira $(22,23$ e 24) do replanejamento escolar. A suspensão das atividades presenciais se deu no dia 23 de março para prevenir a disseminação do coronavírus nas escolas.

'Temos pouco tempo, mas a ideia é ir melhorando e aperfeiçoando o trabalho nas plataformas ao longo dos próximos dias. Queremos simplificar ao máximo a vida dos educadores e dos estudantes, mas precisamos retomar, aos poucos, os nossos processos de aprendizagem', disse o Secretário de Estado da Educação, Rossieli Soares. (SÃO PAULO, 2020a, grifo nosso)

Em outra notícia veiculada no site da Secretaria, em 16 de abril, podemos ler a seguinte manchete: "Alunos vão receber 3,5 milhões de kits com material pedagógico e de orientação para período de aulas em casa". Nesta, esclarece-se as formas de 


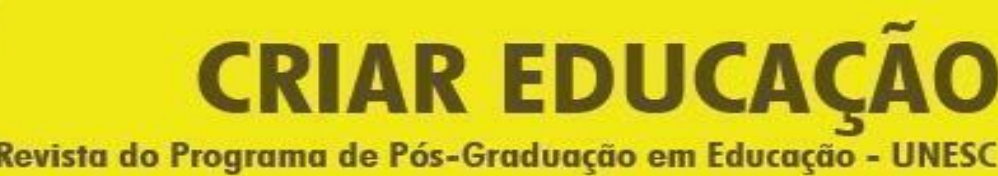

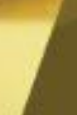
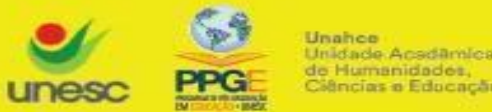

Criar Educação, Criciúma, v. 9, n²2, Edição Especial 2020.- PPGE - UNESC - ISSN 2317-2452

atuação do Governo na Educação Básica pela via da adoção da Educação a Distância no período de pandemia:

[...] distribuição de kits com material impresso contendo apostilas de matemática e língua portuguesa, gibis da Turma da Mônica, livros paradidáticos e manual de orientações às famílias e do Centro de Mídias da Educação de São Paulo (CMSP). (SÃO PAULO, 2020b, grifo nosso)

Aqui, reitera-se que "[...] as aulas que contarão como dias letivos recomeçam no dia 27 de abril", procedimento amparado por deliberação favorável do Conselho Estadual de Educação (CEE), homologada em 19 de março pela SEDUC: "[...] para minimizar as perdas dos alunos com a suspensão das aulas, serão válidos todos os recursos disponíveis, 'desde orientações impressas com textos, estudo dirigido e avaliações enviadas aos alunos/família, bem como outros meios remotos diversos'." (SÃO PAULO, 2020c). Informa-se ainda que a “[...] Seduc também está estruturando como deverá ser feita a comprovação das atividades realizadas a distância para que de fato sejam contabilizadas como dia letivo." (SÃO PAULO, 2020c).

É a partir deste contexto, de volta às aulas mediatizadas também por plataformas online, que se explicita de forma mais detalhada o que seria e qual a função do Centro de Mídias da Educação de São Paulo (CMSP):

O Governo de São Paulo lançou no dia 3 o Centro de Mídias da Educação de SP (CMSP), uma plataforma que vai permitir que os estudantes da rede estadual tenham acesso a aulas ao vivo, videoaulas e outros conteúdos pedagógicos mesmo durante o período do isolamento social.

A partir da próxima semana também estará disponível um segundo aplicativo para download, o CMSP Educação Infantil e Anos Iniciais, com conteúdo exclusivo para essas etapas de ensino. [...]

Além da ferramenta que vai viabilizar o ensino presencial mediado por tecnologia, o Governo de São Paulo também entrou em acordo com a TV Cultura, que vai transmitir as aulas por meio dos canais digitais 2.2 - TV Univesp e 2.3 - TV Educação.

A Seduc vai patrocinar internet para que alunos e professores da rede tenham acesso aos conteúdos via celular, sem qualquer custo. Para isso, firmará contrato com cada uma das quatro maiores operadoras de telefonia: Claro, Vivo, Oi e Tim. 


\section{CRIAR EDUCAÇÃOO}

Revista do Programa de Pós-Graduação em Educação - UNESC

\section{unesc PPGE}

Criar Educação, Criciúma, v. 9, n²2, Edição Especial 2020.- PPGE - UNESC - ISSN 2317-2452

Dessa forma todo estudante da rede poderá desfrutar das atividades do aplicativo sem utilizar o pacote 4 G do celular, sinal de internet wi-fi, ou mesmo quando estiver sem créditos (SÃO PAULO, 2020b, grifo nosso).

As referidas notícias não remetem-se via hiperlinks a uma página do Centro de Mídias da Educação de São Paulo (CMSP), mas uma rápida busca na Internet nos fornece acesso ao endereço [https://centrodemidiasp.educacao.sp.gov.br/]. Nele, além de uma breve apresentação e espaço de notícias, bem como contato e links para download dos aplicativos, encontramos a Programação diária das vídeo aulas transmitidas pelo Centro de Mídia e canais de televisão. Os horários foram prédefinidos pela Secretaria de Educação e, em muitos casos, não coincidem com os horários regulares em que os educandos(as) participavam das aulas presencialmente, como pode ser visto abaixo:

Figura 1 - Exemplo de programação das aulas via Centro de Mídias e canais televisivos

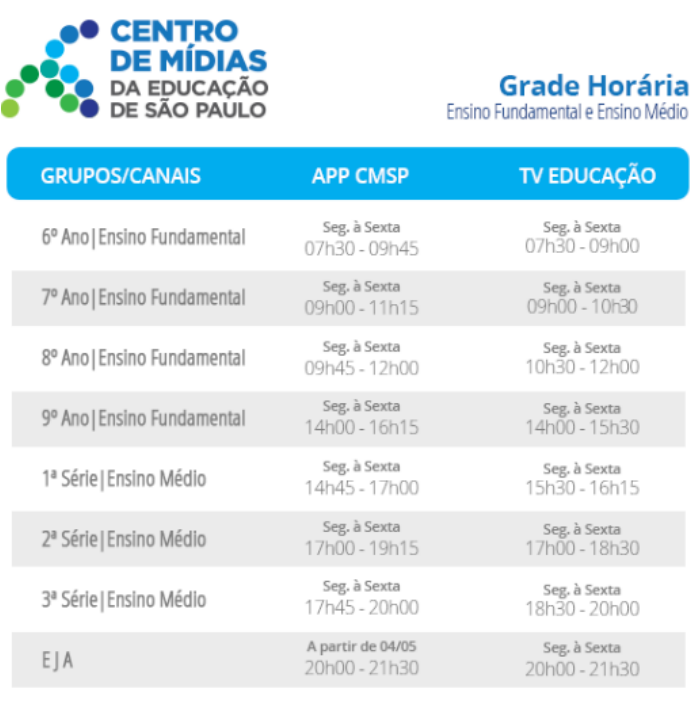

VEJA O NÚMERO DO CANAL DA TV EDUCAÇÃO EM SUA CIDADE

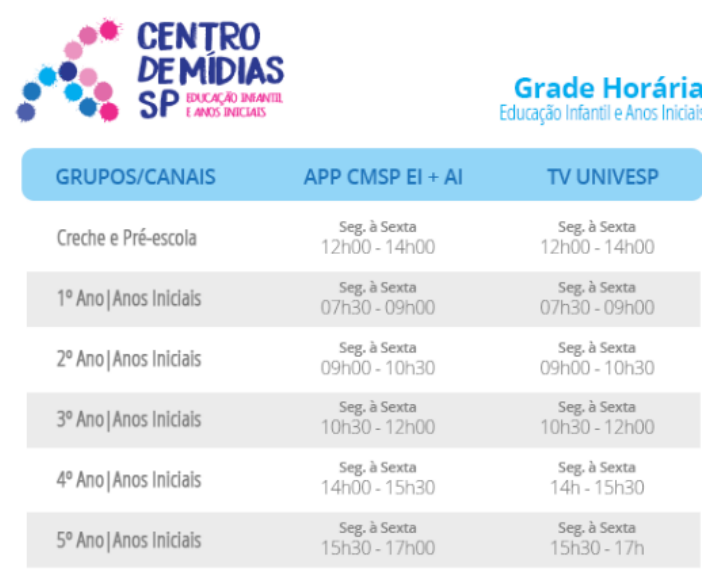

VEjA O NÚMERO DO CANAL DA TV UNIVESP EM SUA CIDADE

Fonte: Site do Centro de Mídias da Educação de São Paulo.

Por fim, encontra-se no referido site um documento de "Perguntas e Respostas", com vistas a esclarecer dúvidas sobre as soluções tecnológicas adotadas. O documento é dividido em 3 blocos: "Questões - Tecnologia”, contendo 48 


\section{CRIAR EDUCAÇÃOO \\ Revista do Programa de Pós-Graduação em Educação - UNESC}

\section{(1)

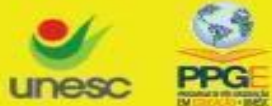

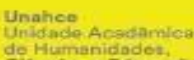 \\ ediunesc}

Criar Educação, Criciúma, v. 9, ํㅡ, Edição Especial 2020.- PPGE - UNESC - ISSN 2317-2452

perguntas e respostas; "Questões - Pedagógicas", contendo 5 perguntas e respostas; "Questões - Gerais", contendo 12 perguntas e respostas². As questões de cunho tecnológico variam desde uma explanação sobre o que é o Centro de Mídias e suas funcionalidades gerais, a questões pontuais sobre como realizar download e acesso do aplicativo, alterar nickname e incluir fotos, dentre outros. Aqui, é informado que o Centro de Mídias

1. [...] foi criado para auxiliar no processo de ensino e aprendizagem, com a utilização de tecnologias para a formação de professores e a transmissão de aulas para os alunos da rede estadual de ensino de São Paulo. Por meio do aplicativo, é possível assistir e participar de aulas, ao vivo, e com interação, com professores da rede estadual e outros especialistas, além de outras programações de educação, cultura e entretenimento com conteúdos desenvolvidos pela Secretaria de Educação e também cedidos por instituições parceiras, pelo celular ou pela TV.

2. O aplicativo oferece aulas ao vivo, diversos canais de comunicação e conteúdos interativos. Os alunos participam das aulas por meio de chat ou vídeo, podem baixar o material da aula, que fica disponível, além de interagir e trocar experiências.

Além das perguntas e respostas, podemos ter uma ideia de como vem sendo a estratégia de alocação de profissionais para ministrar os conteúdos no Centro de Mídia SP, por intermédio da notícia publicada no site da SEDUC "Da sala de aula para a internet: veja como funcionam as aulas com os professores Edutubers" (um neologismo que unifica os termos "Educadores/as" e "Youtubers"):

[...] é professor de geografia e educação digital e, desde 2012, alimenta o seu canal no Youtube. Ele é um dos edutubers escalados para dar aulas no Centro de Mídias São Paulo. De acordo com ele, o objetivo é ter o canal como repositório de matérias e, por conta disso, de um ano e meio pra cá, ele foi reformulado com playlist, sequência de aula e a simulação de um espaço de aprendizagem. [...]

\footnotetext{
${ }^{2}$ Tal forma de divisão das questões, bem como as citações referentes ao documento "Perguntas e Respostas" do site do Centro de Mídias SP, referem-se a versão consultada na semana de 27 de abril a 01 de maio de 2020. Esta versão do documento pode ser acessada em:

https://centrodemidiasp.educacao.sp.gov.br/wp-content/uploads/2020/04/cmsp-perguntas-erespostas.pdf. Atualmente, o documento encontra-se remodelado e disponível para consultas no referido site pelo link: https://centrodemidiasp.educacao.sp.gov.br/downloads/cmsp-perguntas-erespostas.pdf
} 


\begin{abstract}
'Este ainda é um modelo que necessita de uma cultura digital e um aprender digital, e é um processo que está sendo construído no aprendizado digital. Os alunos participam, inclusive, de uma interatividade no Google Forms com uma tarefa parecida com um exercício em aula, e já é notado um avanço por parte deles. Na primeira aula eles responderam 90 respostas em 5 minutos. Na segunda, foram 200 em 3 minutos. É interessante porque eles tinham que acessar vários caminhos, e no fim, acabaram conseguindo'. (SÃO PAULO, 2020d, grifo nosso)
\end{abstract}

É nestes termos que, na semana iniciada no dia 27 de abril, 3,5 milhões de educandos e educandas da maior rede de Educação Básica no Brasil "retornaram às aulas". Por meio de kits educacionais e plataformas digitais em que terão acesso aos conteúdos elaborados por profissionais especificamente selecionados pela SEDUC, tendo em vista o desenvolvimento de "atividades escolares não presenciais" desveladas de um "[...] planejamento e execução da unidade escolar coordenado pela Direção da Escola e Coordenação Pedagógica." (SÃO PAULO, 2020f, p. 1). Conteúdos e atividades que, realizadas, contabilizarão frequência e, portanto, dias letivos, conforme dispõe a Resolução SEDUC nำ 45, de 20 de abril.

Com base no case da Rede Pública de Ensino do Estado de São Paulo, tornarse-ia agora possível re-situarmos o questionamento proposto o início deste ensaio: em que medida experiências de EaD na Educação Básica revelam uma compreensão instrumental da práxis pedagógica, ao passo em que a consubstanciam pelos ditames de uma racionalidade tecnológica?

\title{
4 Racionalidade tecnológica e Educação: a lógica instrumental e os processos formativos (escolares)
}

Marcuse assevera, em suas reflexões sobre a racionalidade tecnológica, que uma das suas principais dimensões constituintes no universo do discurso e pensamento que enseja é a do operacionalismo:

[...] tornar o conceito sinônimo do conjunto correspondente de operações [...] 'para considerar os nomes das coisas como indicativos, ao mesmo tempo, de sua maneira de funcionar, e os nomes das propriedades e dos processos como simbólicos do aparato usado para detectá-los ou produzi-los'. Isso é raciocínio tecnológico, que tende 'a identificar as coisas às suas funções'." (MARCUSE, 2015, p. 109). 
A redução operacional do conceito de suas múltiplas dimensões e possibilidades de compreensão do real, enquanto instrumento par excellence do desenvolvimento do pensamento crítico, configura-o apenas em termos de sua função contingente dentro de um sistema pré-determinado de opções a serem "escolhidas" e tecnicamente agenciadas. Assim, em um exemplo no campo político, "democracia" resume-se a "escolher candidatos em uma eleição a cada 4 anos". Já por "educação" poderíamos dizer que é sinônimo de "transmitir e averiguar a retenção de conhecimentos" - ou seriam informações? Muito longe, portanto, de uma noção de Educação (aqui, com $\mathrm{E}$ maiúsculo) enquanto encontro amoroso de sujeitos dialogantes que buscam significar e transformar o mundo em comunhão (FREIRE, 1977), para valer-nos apenas de uma possível compreensão que pretende desvelar mediações emancipatórias junto aos sujeitos a partir de processos formativos.

É neste sentido que podemos e devemos expor, também com Marcuse, a falsa neutralidade da tecnologia embutida na sua utilização como panaceia para os problemas educacionais. Por trás da adoção de plataformas de entrega de conteúdos e atividades avaliativas, com supostos vieses "modernizantes", supostamente "interativos" e "inovadores", reside uma concepção pedagógica nada neutra - de que educar é treinar, adestrar, transmitir, medir. A operacionalização do conceito de educação, em síntese. Conforme nos alertara Paulo Freire,

Toda vez, porém, que a conjuntura o exige, a educação dominante é progressista à sua maneira, progressista 'pela metade'. As forças dominantes estimulam e materializam avanços técnicos compreendidos e, tanto quanto possível, realizados de maneira neutra. (FREIRE, 1996, p. 99)

Tal racionalidade fica evidente na opção gerencial do Governo do Estado de São Paulo, ao adotar certa compreensão de EaD como estratégia de reposição de aulas presenciais regulares. É a racionalidade da otimização dos recursos pela via da instrumentalidade tecnológica, para não "perder o ano letivo". Pois, conforme afirmou o secretário Rossieli Soares: "[...] é importante que as crianças, principalmente as dos anos iniciais mantenham o ritmo de estudo para que não comprometa o processo de alfabetização: 'Estudos mostram que longos períodos de recesso podem trazer prejuízo à aprendizagem'." (SÃO PAULO, 2020c, grifo nosso). Obviamente, o 
excelentíssimo Secretário não fala que estudos são estes, quais são suas premissas pedagógicas, contexto de escrita, dentre outros elementos importantes para qualquer julgamento qualificado.

De fato, nem precisa: o seu discurso é pontilhado de estruturas autovalidantes como esta, que não requer argumentação e espera dos seus receptores somente a atitude passiva e de respeito a autoridade da expressão "estudos que mostram". Em um contexto pandêmico, o importante enquanto processo formativo é "manter o ritmo de estudo". Reverbera-se aqui uma das características centrais do modo de pensar e comportar-se pautado pela racionalidade tecnológica, expressada no seu universo do discurso: a utilização de "[...] proposições analíticas autovalidantes parecem funcionar como fórmulas mágico-rituais. Marteladas e remarteladas na mente do receptor, elas produzem o efeito de fechá-lo dentro do círculo das condições prescritas pela fórmula." (MARCUSE, 2015, p. 110).

Com vistas a dar conta desta necessidade alfabetizante no contexto pandêmico, assevera-se: "Para o desenvolvimento das atividades escritas, familiares alfabetizados ou professores, à distância, poderão apoiar os alunos e responsáveis no entendimento dos materiais enviados." (SÃO PAULO, 2020e). A racionalidade da padronização do ensinar-aprender enquanto input (entrada) de informações massivas nas mentes dos educandos, em que se aguarda um output (saída) correspondente, mais uma vez é escancarada. O material instrucional é, aqui, o locus em que se coagula tal racionalidade. Uma racionalidade do pensar e comportar-se operacionais que se dirige exclusivamente aos meios ("fazer pela EaD"), sem nunca pensar nos fins e contextos dos processos formativos levado à cabo pela Escola na Educação Básica.

Neste pensar e agir pelo agenciamento técnico de meios direcionados a fins em si mesmos e superimpostos, "currículo" se resume as grades de disciplinas enquanto depositárias dos conteúdos a serem transmitidos aos(as) educandos(as). Em nosso julgamento, currículo deveria constituir-se em um movimento vivo de articulação, crítica e reestruturação dos saberes acumulados historicamente, frente aos diversos problemas e possibilidades concretas que os seres humanos contraem entre si, no desafio pela criação de contextos sociais, políticos, econômicos, estéticos 
e culturais afeitos ao valor da dignidade da vida humana. E isto, repitamos, vai além de uma visão formalista e conteudista de disciplinas e grades curriculares - o que não significa negar a importância dos saberes humanos acumulados historicamente e organizados nas diferentes disciplinas. Mas enquadrar tais saberes na práxis educativa somente pela via das grades disciplinares "normalizadas", do "ano letivo padrão", da necessidade de "manter o ritmo" constitui uma expressão clara da racionalidade que perpassa boa parte dos discursos e ações levadas à cabo, atualmente, na Educação Brasileira - da Educação Infantil ao Ensino Superior.

Não devemos olvidar que a Escola em seus currículos, enquanto instituição legada pela Modernidade para a formação humana cidadã, não resume (ou não deveria resumir) a práxis educativa tão somente em sua dimensão cognitiva - sequer esta, ao nosso ver, tais experiências aligeiradas de EaD dão conta. A Escola é (ou deveria ser) um espaço de formação cidadã que envolve dimensões estéticas, afetivoemocionais, ético-políticas e culturais, tornadas conscientes e objeto de formação dos educandos por uma série de mediações que envolvem interações humanas qualificadas e diversidade de espaços e tempos de ensinar-aprender.

Uma das consequências nefastas da racionalidade embutida nas opções aligeiradas de adoção da EaD em tempo de pandemia trata-se do rebaixamento da autoridade docente, sua diluição em plataformas tecnológicas, na figura dos pais/mães ou responsáveis, na atividade de "especialistas e youtubers". Enquanto estratégia de poder, advoga pelo enfraquecimento da categoria enquanto classe trabalhadora consciente do seu papel social, em um contexto no qual a regra é a falta de diálogo com os(as) educadores(as) na definição das opções adotadas.

Em última instância, constitui-se mesmo no rebaixamento do ensino (escolar), em sua relação dialética com a aprendizagem, enquanto unidades complementares que desvelam a formação de homens e mulheres enquanto processo de humanização, tanto dos educandos(as) quanto dos educadores(as). Não é de hoje que documentos orientadores e legislações, bem como diversas publicações acadêmicas no campo de pesquisa da Educação a Distância (EaD) e das Tecnologias Educacionais, qualificam tais processos como "de aprendizagem" somente. $O$ ensino, em sua dimensão de intervenção educativa consciente, pautada em princípios 


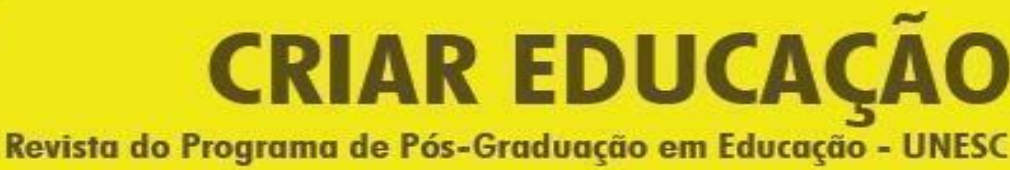

\section{unesc PPGE}

Criar Educação, Criciúma, v. 9, nำ2, Edição Especial 2020.- PPGE - UNESC - ISSN 2317-2452

político-pedagógicos, passa a ser relegado às plataformas tecnológicas; o(a) educador(a), um mero facilitador da (auto)aprendizagem dos alunos. (MALAGGl; SILVA; TEIXEIRA, 2018). Tudo isto "embalado" em noções pedagógicas sem nenhuma correlação com uma compreensão séria do que seja a formação humana, como as noções de "autoaprendizagem", de uma aprendizagem derivada dos próprios materiais didáticos ou de interações reificadas, para os quais a intervenção pedagógica é transferida de forma instrumental.

Esta forma irracional de pensar racionalmente a Educação revela a sua faceta mais desumana quando analisamos uma série de mediações extra-escolares e extraeducação. Condicionantes socioeconômicos que afetam a educação (escolar) e que sequer são levados em consideração na adoção acrítica da EAD, enquanto paliativo em tempos de crise - como a que vivemos atualmente na pandemia de coronavírus. No documento "Guia COVID-19: Educação e proteção de crianças e adolescentes", elaborado pela Campanha Nacional pelo Direito à Educação, tais questões são ressaltadas na análise das situações que levam ao fracasso escolar:

As razões para o fracasso escolar são múltiplas, segundo o Unicef (Fundo das Nações Unidas para a Infância). Entre elas estão:

1. a falta de condições básicas de segurança alimentar;

2. a falta de acesso a insumos de qualidade, como tecnologia e Internet;

3. a falta de conexão entre o que é ensinado e a realidade dos estudantes, o que provoca um profundo desinteresse;

4. a discriminação em relação a crianças e adolescentes pobres, LGBT, com deficiência, negros ou indígenas;

5. a gravidez na adolescência; e

6. a necessidade de trabalhar. (CAMPANHA NACIONAL PELO DIREITO À EDUCAÇÃO, 2020, p. 13)

Em tempos de enfrentamento de uma pandemia mundial, que afeta a todos(as) de diversas formas mas, sobretudo, as famílias mais pobres da classe trabalhadora em todos os itens ressaltados na citação acima (alimentação, acesso, discriminação, etc.), seria de se pressupor que Gestores da Educação levassem em conta todos estes condicionantes que podem estar presentes, em diferentes níveis e graus de articulação, na vida de milhões de crianças e jovens brasileiros. Que contexto qualificado de ensino-aprendizagem teria, portanto, uma criança acessando de forma 


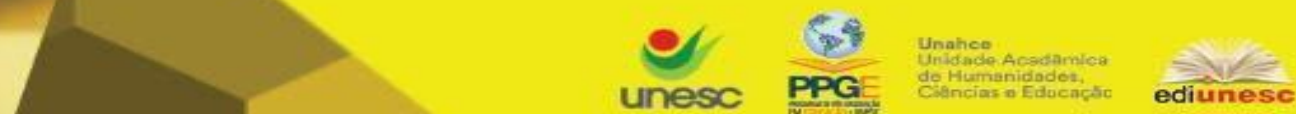

Criar Educação, Criciúma, v. 9, ํㅡ, Edição Especial 2020.- PPGE - UNESC - ISSN 2317-2452

precária plataformas digitais em um celular, nas periferias de uma cidade como São Paulo, em que muitos pais/mães ou responsáveis buscam desesperadamente colocar na mesa o pão "daquele dia"? Espera-se que estes pais/mães sejam mediadores qualificados de um processo educativo pautado em uma versão desqualificada da $\mathrm{EaD}$, enquanto homeschooling?

O que se verifica, portanto, é mais uma faceta desta racionalidade tecnológica que pensa ser possível padronizar para transferir práticas e concepções do Ensino Presencial para a Educação a Distância, quando ambos deveriam ser tratados com um mínimo de seriedade político-pedagógica, ainda mais frente ao contexto pandêmico. É a própria especificidade da EaD, o papel que tal modalidade educativa pode ter nos processos formativos da Educação Básica, que está em jogo neste momento. É interessante pensarmos como a própria estrutura de "necessidade autovalidante" cria discursos e práticas de suposta inclusão digital neste processo de "volta das aulas EaD". Contudo, de uma inclusão digital subalterna, que opera segundo a lógica do "incluir excluindo".

Como o problema educacional é percebido de forma técnica, as respostas aos diversos entraves postos para superá-lo, advindos da forma de pensar pautada pela racionalidade tecnológica, ocorre em parâmetros semelhantes. Assim, se o problema era o acesso à Internet nos celulares de educandos(as) e educadores(as), o Estado de São Paulo firma parceria com as maiores operadoras de telefonia do Brasil e provê livre trânsito destes sujeitos ao mundo digital. "Livre trânsito", porém, circunscrito a navegação no aplicativo Centro de Mídias. Cria-se, pois, um aplicativo enquanto "curral digital" (LEMOS, 2000), em que toda a potencialidade das redes e da própria cultura digital em termos formativos passa a ser obliterada. Aos filhos da classe

\footnotetext{
${ }^{3}$ Neste sentido, fazemos coro às problematizações que Ventura (2020) destaca acerca do homeschooling, possível forma na qual a panaceia tecnológica criticada neste ensaio pode resultar "regra" a ser aplicada no contexto "pós-pandemia". Entendemos não ser descabida a possibilidade do homeschooling aliado a um instrumentalismo pedagógico via EAD como estratégia de desmonte da Escola Pública no contexto pós-pandêmico. Basta lembrar que a regulamentação da educação domiciliar foi situada como uma das metas prioritárias dos 100 primeiros dias do governo Bolsonaro, conforme notícia veiculada em: https://g1.globo.com/educacao/noticia/2019/01/23/regulamentar-aeducacao-domiciliar-e-uma-das-metas-prioritarias-dos-100-primeiros-dias-do-governobolsonaro.ghtml.
} 


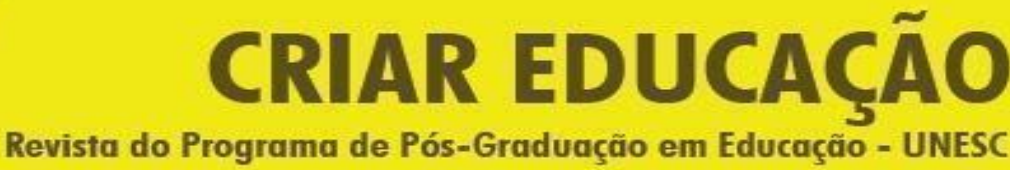

\section{O \\ unesc PPGE \\ ediunesc}

Criar Educação, Criciúma, v. 9, n²2, Edição Especial 2020.- PPGE - UNESC - ISSN 2317-2452

"média" e "alta", certamente este não será um problema: seus responsáveis podem dispor de condições para manter uma conexão à Internet paga para além do aplicativo. Poderão, assim, valer-se de demais espaços de pesquisa, interação e acesso à informações que serão restritos a grande maioria da população.

Maria Helena Bonilla e Paulo Cezar de Oliveira, citando a pesquisadora Marlene Ribeiro no artigo Inclusão digital: ambiguidades em curso, asseveram como

'[...] a luta pela inclusão é também uma luta para manter a sociedade que produz a exclusão', implica, a aceitação da ordem que 'exclui'. Inserir supõe conceber os sujeitos passivos como peças de um jogo, designando a eles 'um papel de meros objetos, seres amorfos que aceitam a inexorabilidade de sua exclusão’. (BONILLA; OLIVEIRA, 2011, p. 28)

Novamente temos aqui configurada uma compreensão operacional de conceitos que deveriam permitir a reflexão crítica de situações e contextos sociais. Inclusão digital, um conceito ressaltado pelas autoras acima citadas como problemático em suas diversas implicações teóricas e práticas, volta a ser resumido ao "dar acesso (precarizado) à Internet". Internet aqui não é um direito público e humano universal, é um paliativo para dar conta de uma dada situação em que se necessita "fazer algo", "não parar sob hipótese alguma", "manter o ritmo".

Poderíamos ainda problematizar nesta "inclusão digital subalterna" questões outras envolvidas na configuração das "soluções tecnológicas" enquanto panaceia tecno-educacional. Por exemplo, a segurança e privacidade dos dados de milhões de educandos(as) e professores(as) em uma plataforma criada e "doada" por uma empresa privada - no caso do Centro de Mídia, a IP.TV. Quais são as garantias que tais dados não serão utilizados para fins outros que não os educacionais e contingenciais do contexto pandêmico, resguardado o direito à privacidade? Como saber se tais empresas não utilizarão dados sem consentimento e esclarecimento devido aos sujeitos, para "modelar" novas plataformas e propostas de cursos a serem 


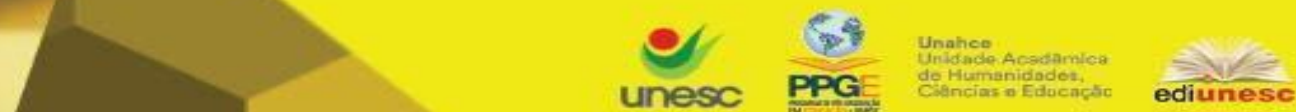

Criar Educação, Criciúma, v. 9, ํㅡ, Edição Especial 2020.- PPGE - UNESC - ISSN 2317-2452

posteriormente vendidos, dando prosseguimento ao "case inovadore de sucesso" que foi a EaD em tempos de pandemia ${ }^{4}$ ?

Felizmente, tal pensar operacional confronta-se com percepções outras sobre inclusão digital, como a que citamos abaixo retirada da nota "A escola pública e as ações do Governo de SP frente à pandemia de COVID-19: questões em aberto":

\begin{abstract}
Como bem público, o acesso à internet é recurso essencial à formação dos estudantes e às suas práticas regulares de estudo e pesquisa. Enquanto a gratuidade do 'pacote' de dados oferecido pelo programa de inclusão digital do governo de São Paulo limita-se ao acesso ao 'Centro de Mídias SP', os estudantes das classes média e alta têm menos dificuldades para prosseguir com seus estudos nas escolas privadas por possuírem computadores, smartphones e conexão à internet com certas características, bem como condições ambientais propícias ao estudo em casa. Logo, o governo de São Paulo deveria prover acesso amplo à internet como forma de inclusão social e cidadã dos estudantes da rede estadual.
\end{abstract}

Isso também facultaria às famílias mais pobres do estado de São Paulo o acesso a informações mais qualificadas sobre a pandemia e os protocolos de saúde pública para a sua contenção, afastando a enxurrada de desinformação e de notícias falsas que chegam, sobretudo, por meio de aplicativos de comunicação de uso coberto pelos pacotes de dados mais baratos do mercado. A política educacional emergencial do governo de São Paulo, portanto, deveria abarcar também as famílias dos estudantes. (REDE ESCOLA PÚBLICA E UNIVERSIDADE; GRUPO ESCOLA PÚBLICA E DEMOCRÁTICA, 2020, p. 3, grifo do autor)

Diríamos aos(as) colegas educadores(as) desta nota: assim seria se compreendêssemos, por exemplo, que a educação escolar deve perpassar por interações qualificadas com os contextos sociais diversos pelos quais as crianças e jovens transitam, entre elas, a família. Parece óbvio que este não é o entendimento que configura as ações da Secretaria do Estado de São Paulo no contexto de adoção da EAD para reposição de aulas regulares. As famílias adentram no discurso oficial somente quando se faz necessário outorgar-lhes tarefas que não lhes cabem, como a de serem docentes de seus filhos(as).

\section{Tecnologia, pandemia e educação: que nos resta fazer e pensar?}

\footnotetext{
${ }^{4}$ Sobre a presença da IP.TV no case paulista, a reportagem a seguir é luminar para a compreensão das relações escusas entre poder político-econômico, ideológico e tecnologias:

https://theintercept.com/2020/06/15/app-empresa-tv-bolsonaro-aulas-online-pandemia/.
} 
Com vistas ao que foi exposto, não parece ser demasiado "alarmista" aferir que a "questão EaD" na Educação Básica se tornará ainda mais presente nos discursos e propostas educacionais, durante e após o contexto pandêmico ter se "normalizado" uma das intencionalidades por detrás dos movimentos agora ensaiados? $\mathrm{O}$ case paulista, narrativa devidamente construída como um sucesso - basta lermos as notícias publicadas no site da Secretaria de Educação, quase sempre em tons ufanistas -, poderá ser um norteador para soluções "inovadoras".

Em suma: tal tendência poderia estar configurando uma conversão cada vez mais totalitária da práxis educativa e do papel social-formativo da Educação Pública pela Escola em um sistema de treinamento do ser humano? Lembramos aqui que "tecnologia" não significa, em Marcuse, um dado artefato técnico em específico. Tratase, para além disto, de um modo de produção da existência social que conforma um pensar e comportar-se baseado na apreensão do real enquanto "sistema hipotético de instrumentalidades" (MARCUSE, 2015, p. 161). Ou seja, aquilo que é capaz de ser mensurado, ordenado, manipulado e controlado tecnicamente a partir da adequação de meios a fins dados a priori, sem que tais causas finais do agir técnico sejam elemento de discussão e análise crítica coletiva. A educação assim compreendida e realizada instrumentalmente, configura-se como elemento tático de controle social em termos de uma adaptação positiva dos homens e mulheres a um aparato social altamente racionalizado em termos tecnológicos. Os artefatos técnicos agenciados no campo educacional configuram-se, assim, como objetivações por meio das quais tal racionalidade pode ser capilarizada nos processos formativos, nas relações de ensinar-e-aprender.

Infelizmente, a ideologia que esta racionalidade tecnológica conforma afeta a todos(as) os envolvidos nos processos formativos pela via da educação escolar. Não é incomum, em uma rápida navegação por espaços digitais de interação da classe trabalhadora da educação com suas entidades representativas, lermos falas como esta: "O que querem vocês dos sindicatos, parar o período letivo e daí todo mundo deixa de receber?", "O Governo não vai dar salário para quem não trabalhar", "Como ficarão os ACTs?". O que se está perdendo em tais falas e posicionamentos é a capacidade do pensamento "negativo", "disruptivo", a análise crítica e de totalidade 


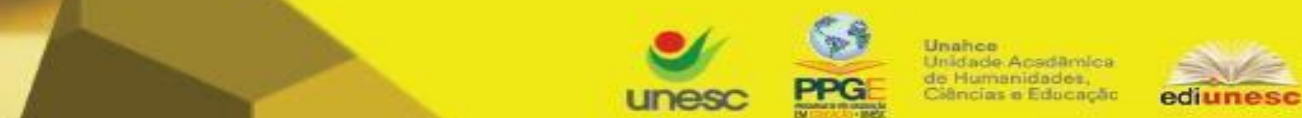

Criar Educação, Criciúma, v. 9, №2, Edição Especial 2020.- PPGE - UNESC - ISSN 2317-2452

que Marcuse (2015) nos aponta obliterada pela racionalidade tecnológica. As questões essenciais, que miram as estruturas da sociedade em suas múltiplas formas de manutenção da opressão, não são vislumbradas e problematizadas.

É pouco problematizada em termos de sujeitos políticos coletivos do campo educacional, com a força popular necessária para tornar-se práxis política de transformação radical da realidade, o fato de a produção de riquezas no Brasil estar atualmente nas mãos de alguns poucos bilionários, aquele $1 \%$ que não paga quaisquer impostos sobre lucros e dividendos dos seus capitais financeiros, muitos deles de cunho especulativo ${ }^{5}$. Lucros que só fazem aumentar suas grandes fortunas pessoais, ao passo em que a imensa maioria da classe trabalhadora paga impostos demais com o pouco que tem, em alguns casos retidos na fonte - quando se têm o luxo de um trabalho com carteira assinada, em um país com mais de $40 \%$ das vagas ocupadas em empregos informais ${ }^{6}$.

Não deveria causar fortes reações populares o fato de o Governo Federal ter transferido $\mathrm{R} \$ 1,2$ trilhões aos bancos para "irrigarem a economia", "dar liquidez aos mercados" e, assim, "poderem enfrentar a crise" - dinheiro público repassado com juros abaixo da Taxa Básica SELIC (que está hoje está em 3,5\%). Dinheiro atualmente "empossado" nos bancos e que não chega aos pequenos/médios empresários e a população em geral, porque os bancos não têm interesse em ser apenas um instrumento de repasse de dinheiro a população, ou seja, desejam lucrar sobre esse valor ${ }^{7}$. E, em um contexto de "incertezas econômicas" geradas pela pandemia, emprestar dinheiro sem cobrança de altos juros e uma infinidade de requisitos que assegurem a possibilidade de pagamento, não é um "bom negócio" - para os bancos, óbvio.

\footnotetext{
${ }^{5}$ Sucessivos relatórios publicados pela Oxfam Brasil dão conta do aumento cada vez mais predatório da concentração de riquezas em nosso país. Tais relatórios podem ser acessados em: https://www.oxfam.org.br/.

${ }^{6}$ Conforme informações presentes neste link: https://agenciabrasil.ebc.com.br/economia/noticia/202003/informalidade-cai-mas-atinge-38-milhoes-de-trabalhadores.
}

\footnotetext{
${ }^{7}$ Para maiores informações sobre tal medida econômica do Governo Federal, acessar o link https://www1.folha.uol.com.br/mercado/2020/03/desafio-do-bc-e-fazer-r-12-tri-sair-dos-bancos-paraempresas-e-familias. shtml?aff source=56d95533a8284936a374e3a6da3d7996.
} 
Se tais montantes de [nossos] recursos públicos estão nas mãos de pequenos grupos de pessoas e de Governos, que os utilizam para ganhar ainda mais dinheiro na crise, não seria importante perguntar: "e porque, para a Educação, nada?". "Porque, para a Saúde, tão pouco frente ao necessário imenso que se coloca à nossa frente?". O sucateamento e rebaixamento pedagógico derivado de uma volta às pressas via EaD é algo inexorável? Não deveríamos estarmos nós - educadores(as), educandos(as) e todos àqueles(as) preocupados com o papel da Educação na formação humana integral -, demandando que o Estado cumpra com o seu papel de garantir condições equânimes de vida neste momento? Inclusive com a manutenção de todos os postos de trabalho com salários em dia aos seus profissionais da Educação? Garantia a ser estendida a todos(as) os trabalhadores brasileiros que necessitam neste momento, por meio de uma renda universal básica digna?

Não se trata, como alguns "analistas e formadores de opinião" procuram destacar em suas falas pontilhas de ideologia dominante, receber do Estado sem nada fazer. Situando tal análise no caso educacional, objeto da nossa fala, se trata de no momento adequado, com as condições mínimas dadas (inclusive de segurança e saúde), recuperar aquilo que não foi possível desenvolver em aulas regulares que contabilizem dias letivos. Significa colocar a possibilidade de termos um ciclo letivo 2020-2021. Pois, conforme destaca o "Posicionamento ao Parecer do CNE que trata da Reorganização dos Calendários Escolares e a realização de atividades pedagógicas não presenciais durante o período de Pandemia da COVID-19", assinado por diversas entidades ligadas à pesquisa e formação educacional, "O ano letivo não precisa coincidir com o ano civil, principalmente em situações excepcionais como a que nos encontramos." (ANPED et al., 2020, p. 2).

"E o que fazer então neste momento, ou querem ganhar sem fazer nada", dirão alguns? Cito novamente a nota da Rede Escola Pública e Universidade (REPU) e Grupo Escola Pública e Democrática (GEPUD), como apenas um exemplo de vislumbre de pensamento "negativo e disruptivo":

Afirmamos desde já que, ante uma tragédia dessas proporções, nenhuma proposta de "ensino a distância" pode se dar em nome da mera necessidade de repassar conteúdos aos estudantes, nem de uma 


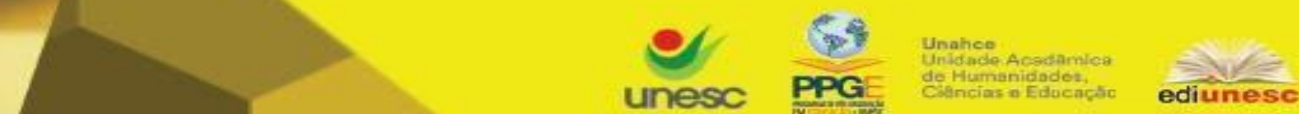

Criar Educação, Criciúma, v. 9, ํㅡ, Edição Especial 2020.- PPGE - UNESC - ISSN 2317-2452

necessidade burocrática de concluir 0 ano letivo para diminuir as perdas financeiras das redes de ensino com reposições de aulas. Isso não quer dizer que atividades a distância não possam acontecer, mas que os 'conteúdos' a serem preservados precisam ser outros.

\begin{abstract}
Os eventuais encontros virtuais entre estudantes e professores não devem ser espaços de transmissão de conteúdos pura e simples, mas de promoção de diálogos e de fortalecimento de laços de solidariedade, sendo este o melhor apoio que se pode dar à formação e ao desenvolvimento das crianças e adolescentes em um momento tão difícil. Tais encontros, além disso, devem reforçar a dimensão pública da escola e o seu papel de formação para a cidadania, valorizando todos os profissionais da educação e estimulando-os a atuarem, junto às suas escolas e redes de ensino, na defesa dos direitos de crianças e adolescentes e do direito à educação. (REDE ESCOLA PÚBLICA E UNIVERSIDADE; GRUPO ESCOLA PÚBLICA E DEMOCRÁTICA, 2020, p. 2, grifo do autor)
\end{abstract}

Terminamos o presente ensaio em tons de totalidade social frente à pandemia, porque a adoção da EaD na Educação Básica, como no case paulista, é apenas um elemento de uma miríade de posições (astutamente) equivocadas. Paulo Freire (2010, p. 172-173) nos lembra, de forma crítica, que a educação nada muda; quem muda as circunstâncias são os sujeitos pelas suas ações concretas na realidade. A educação, porém, pode nos dar "pensamento em perspectiva" para intencionar situá-lo para além dos parâmetros da racionalidade tecnológica, exposta por Marcuse (2015). Obliterar esta capacidade disruptiva e negativa do pensamento é objeto constante daqueles que desejam que as coisas fiquem como estão. A Educação, por fazer parte desta totalidade, não poderia residir de forma indiferente. Cabe a nós tentarmos organizar os contrapontos, teórica e praticamente, "daquilo que é" e "daquilo que virá" a partir da crise humana e civilizacional em potencial, derivada da pandemia COVID-19.

\section{Referências}

ANPED et al. Posicionamento ao Parecer do CNE que trata da Reorganização dos Calendários Escolares e a realização de atividades pedagógicas não presenciais durante o período de Pandemia da COVID-19. 2020. Disponível em: $<$ http://www.anped.org.br/sites/default/files/images/doc-entidades-nacionais-cne23abril20.pdf>. Acesso em: 07 maio 2020.

BONILLA, Maria Helena Silveira; OLIVEIRA, Paulo Cezar Souza. Inclusão digital: ambiguidades em Curso. In: BONILLA, Maria Helena Silveira; PRETTO, Nelson De Luca. (Orgs.). Inclusão digital: polêmica contemporânea. Salvador: EDUFBA, 2011. p. 23-48. 
CAMPANHA NACIONAL PELO DIREITO À EDUCAÇÃO. Guia COVID-19:

Educação e proteção de crianças e adolescentes. 2020. Disponível em: <https://media.campanha.org.br/acervo/documentos/COVID-19 Guia1 FINAL.pdf>. Acesso em: 04 maio 2020.

FREIRE, Paulo. Ação cultural para a liberdade: e outros escritos. 13.reimp. São Paulo: Paz e Terra, 2010.

FREIRE, Paulo. A máquina está a serviço de quem? Revista BITS, [S.I.], p. 6, maio 1984.

FREIRE, Paulo. Extensão ou comunicação?. São Paulo: Paz e Terra, 1977.

FREIRE, Paulo. Pedagogia da autonomia: saberes necessários à prática educativa. 31 ed. São Paulo: Paz e Terra, 1996.

KELLNER, Douglas. Tecnologia, guerra e fascismo: Marcuse nos anos 40. In: MARCUSE, Herbert. Tecnologia, guerra e fascismo. São Paulo: Fundação Editora da UNESP, 1999. p. 21-69.

LEMOS, André. Morte aos portais. 2000. Disponível em: $<$ https://www.facom.ufba.br/ciberpesquisa/andrelemos/portais.html>. Acesso em: 15 jun. 2020.

MALAGGI, Vitor; DA SILVA, Juliano Tonezer; TEIXEIRA, Adriano Canabarro. "O senhor me ouve, pensa e repensa, e rediz, então me ajuda": notas freirianas sobre a relação educador-educando no ensino-aprendizagem on-line. Revista Linhas, Florianópolis, v. 19, n. 41, p. 182-212, set./dez. 2018. Disponível em: $<$ http://www.revistas.udesc.br/index.php/linhas/article/view/1984723819412018182/p df $>$. Acesso em: 15 jun. 2020.

MARCUSE, Herbert. O homem unidimensional: estudos da ideologia da sociedade industrial avançada. São Paulo: EDIPRO, 2015.

MARCUSE, Herbert. Algumas implicações sociais da tecnologia moderna. In: MARCUSE, Herbert. Tecnologia, guerra e fascismo. São Paulo: Fundação Editora da UNESP, 1999. p. 73-104.

MARX, Karl. O capital: crítica da economia política: livro I. 31.ed. Rio de Janeiro: Civilização Brasileira, 2013.

REDE ESCOLA PÚBLICA E UNIVERSIDADE; GRUPO ESCOLA PÚBLICA E DEMOCRÁTICA. A escola pública e as ações do Governo de SP frente à pandemia de COVID-19: questões em aberto. 2020. Disponível em: 
$<$ https://www.cedes.unicamp.br/dl/1jbjV\%2ATA0 MDA 12728>. Acesso em: 05 maio 2020.

SÃO PAULO. Resolução SEDUC 45, de 20-4-2020. Dispõe sobre a realização e o registro de atividades escolares não presenciais pelas unidades escolares vinculadas ao Sistema de Ensino do Estado de São Paulo, durante o período de restrição das atividades presenciais devido à pandemia de COVID19. Diário Oficial [do] Estado de São Paulo, Poder Executivo, São Paulo, SP, 22 abr. 2020f. v.130, n.77, p. 1.

SÃO PAULO. Secretaria da Educação. Alunos vão receber 3,5 milhões de kits com material pedagógico e de orientação para período de aulas em casa. 2020b. Disponível em: <https://www.educacao.sp.gov.br/noticias/governo-de-spentrega-35-milhoes-de-kits-com-material-pedagogico-e-de-orientacao-para-periodode-aulas-em-casa/>. Acesso em: 29 abr. 2020.

SÃO PAULO. Secretaria da Educação. Da sala de aula para a internet: veja como funcionam as aulas com os professores Edutubers. 2020d. Disponível em: $<$ https://www.educacao.sp.gov.br/noticias/da-sala-de-aula-para-internet-veja-comofunciona-aulas-com-os-professores-edutubers/>. Acesso em: 30 abr. 2020.

SÃO PAULO. Secretaria da Educação. Educação entrega 3,5 milhões de kits com material pedagógico e de orientação para período de aula em casa. 2020e.

Disponível em: <https://www.educacao.sp.gov.br/destaque-home/1557621/>. Acesso em: 01 maio 2020.

SÃO PAULO. Secretaria da Educação. Educação SP homologa ensino a distância para alunos da rede estadual no período de suspensão das aulas. 2020c. Disponível em: <https://www.educacao.sp.gov.br/destaque-home/educacaosp-homologa-ensino-distancia-para-alunos-da-rede-estadual-no-periodo-desuspensao-das-aulas/>. Acesso em: $30 \mathrm{abr}$. 202c0.

SÃO PAULO. Secretaria da Educação. Educadores já podem se replanejar para a volta às aulas no dia 27. 2020a. Disponível em:

$<$ https://www.educacao.sp.gov.br/destaque-home/educadores-ja-podem-sereplanejar-para-volta-aulas-no-dia-27/>. Acesso em: 28 abr. 2020.

PINTO, Álvaro Vieira. O conceito de tecnologia. Rio de Janeiro: Contraponto, 2015. v.1.

VENTURA, Lidnei. Homeschooling ou a educação sitiada no intèrieur: notas a partir de Walter Benjamin. Práxis Educativa, Ponta Grossa, v. 15, e2014815, p. 1-18, 2020. Disponível em: $<$ https://revistas.apps.uepg.br/index.php/praxiseducativa/article/download/14815/209 209213292>. Acesso em: 04 maio 2020. 


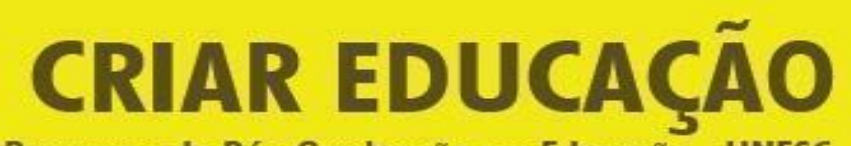

Revista do Programa de Pós-Graduação em Educação - UNESC

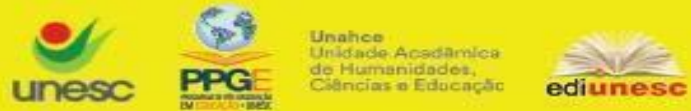

Criar Educação, Criciúma, v. 9, n²2, Edição Especial 2020.- PPGE - UNESC - ISSN 2317-2452

Recebido abril de 2020

Aprovado junho de 2020 